\title{
ROTATIVIDADE E SALÁRIOS NO MERCADO DE TRABALHO FORMAL NO BRASIL ALGUMAS EVIDÊNCIAS EMPÍRICAS PARA O ANO DE 2015
}

Vladimir Sipriano Camillo ${ }^{1}$

Wilson $\mathrm{Abreu}^{2}$

João Vitor Silva Abreu ${ }^{3}$

\section{RESUMO}

O objetivo específico é identificar como a rotatividade no mercado de trabalho formal brasileiro produz rebaixamento salarial. O objetivo secundário é inferir sobre os impactos da rotatividade sobre a desigualdade da renda do trabalho nacional. Para atingi-lo, o texto foi dividido em duas partes. $\mathrm{Na}$ primeira parte foi descrita, de forma sucinta, parte da literatura nacional sobre rotatividade. $\mathrm{Na}$ segunda e última, foram construídas algumas evidências empíricas exploratórias com o propósito de se identificar a magnitude dos impactos da rotatividade sobre os salários dos admitidos em 2015. Dentre os resultados, destacam-se o significativo impacto da rotatividade sobre os maiores salários, comprimindo-os, além da correlação negativa entre a produtividade do trabalho e a rotatividade no mercado formal de trabalho no Brasil.

Palavras-chave: Estrutura produtiva; Rotatividade; Rebaixamento salarial.

1 Professor dos cursos de Economia da Fundação Santo André e Universidade São Judas Tadeu.

2 Mestre em Políticas Públicas pela UFABC e coordenador do Observatório Econômico de Diadema.

3 Graduando em Economia pela UFABC e membro do Observatório Econômico de Diadema. 


\section{INTRODUÇÃO}

A rotatividade é uma força do lado da demanda por trabalho que geralmente é subestimada em sua capacidade de reduzir os salários e a desigualdade da renda do trabalho. $\mathrm{O}$ crescimento econômico nacional, quando ocorre, movimenta a estrutura produtiva da economia brasileira e estimula o aumento da rotatividade. Este crescimento cria uma demanda por trabalho e emprego predominantemente de baixa e média qualificação, propícia para atividades econômicas de alta rotatividade. Esta rotatividade também compromete a ampliação da produtividade do trabalho, porque impede que o trabalhador adquira experiência e qualificação. Embora a literatura nacional descreva a compressão salarial gerada pela rotatividade, buscou-se avaliar este impacto por meio de uma desagregação por níveis de escolaridade. A rotatividade rebaixa mais os salários dos mais qualificados, aproximando-os dos menores e atenuando a queda da desigualdade da renda do trabalho.

$\mathrm{Na}$ primeira parte foram selecionadas algumas abordagens sobre a rotatividade, tentando conectá-la aos salários e, em menor medida, com a desigualdade. A estrutura produtiva nacional é o ponto de partida. A partir desta estrutura tenta-se mostrar como o crescimento a expande e cria um tipo particular de demanda por trabalho voltado para empregos formais de baixa e média qualificação, suscetíveis a rotatividade contínua. $\mathrm{O}$ "tipo" de crescimento econômico brasileiro não parece descrever uma trajetória similar ao modelo neoschumpeteriano, intensivo em inovações, tampouco capaz de promover uma mudança estrutural no produto, no emprego e na produtividade. A estrutura produtiva nacional conta com um amplo mercado de trabalho formal e flexível, amparado numa legislação trabalhista que se propõe a proteger o trabalhador, mas que não restringe a rotatividade.

A segunda parte busca reunir evidências empíricas exploratórias sobre a rotatividade e seus impactos sobre os salários de alguns níveis de escolaridade do mercado formal de trabalho, para o ano de 2015. São exploratórias porque parte das conexôes causais não são tão robustas e as metodologias das evidências empíricas são elementares do ponto de vista econométrico e estatístico. Também deve-se considerar que a análise empírica trabalha com amostras cross sections apenas para o ano de 2015, deixando de se ter uma perspectiva maior de tempo. São estatísticas descritivas e três grupos de regressões lineares simples. Desta forma, a metodologia adotada segue dois procedimentos: um teórico e outro empírico. Antes da apresen- 
tação dos resultados empíricos, foi construída uma síntese teórica com os principais aspectos da literatura nacional parcialmente descrita.

\section{ROTATIVIDADE NO BRASIL: ALGUNS ASPECTOS DA LITERATURA NACIONAL}

$\mathrm{Na}$ literatura nacional há abordagens que procuram explicar as causas da rotatividade. Uma primeira abordagem associa a rotatividade aos ciclos econômicos, mostrando-a como pró-cíclica (MACEDO e CHAHAD, 1985 apud DIEESE, 2011; RAMOS e CARNEIRO, 2002). Desta forma, a rotatividade se amplia durante o ciclo ascendente de crescimento econômico e se reduz no ciclo de baixo crescimento econômico. No ciclo ascendente as empresas ampliam a rotatividade porque estão experimentando os empregados por tentativa e erro, até que, supostamente, encontrem os mais adequados. Esta "experimentação" ocorre porque predomina uma demanda por trabalhadores de baixa e média qualificação. Do lado dos trabalhadores, surgem novas oportunidades ocupacionais abertas pelo crescimento econômico, levando-os a trocar o emprego na expectativa de melhores salários e carreiras (DIEESE, 2011). Contudo, é importante considerar que o crescimento econômico nacional se correlaciona com a rotatividade por meio de uma particular estrutura produtiva, que pode ser parcialmente visualizada por meio da seguinte hipótese:

i) A estrutura produtiva brasileira é polarizada: de um lado, predominam atividades econômicas mais tradicionais, de baixa e média intensidades tecnológicas, que demandam uma força de trabalho de menor qualificação e de baixa remuneração; de outro lado, há poucas atividades mais avançadas, com elevada intensidade tecnológica, que demandam um tipo de trabalho mais qualificado e de melhor remuneração. Sendo assim, a estrutura produtiva gera uma polarização em termos tecnológicos e salariais, mantendo elevada a dispersão salarial e a desigualdade de renda. Na primeira década de 2000, houve uma maior demanda por trabalho com baixa e média qualificação, expandindo seus rendimentos (embora continuem relativamente baixos) e aproximando-os dos ocupados de maior qualificação que perderam participação na renda do trabalho em função de uma menor demanda por trabalho de maior qualificação. ${ }^{4}$

4 Esta hipótese foi enunciada por Camillo (2014) em sua pesquisa de pós-doutorado na PUC-SP. 
As atividades econômicas mais tradicionais contribuem com a rotatividade porque há uma relativa facilidade em se contratar trabalhadores menos qualificados, com menor escolaridade e desta forma mais suscetíveis ao movimento de admissão e desligamento gerado pela rotatividade. "Particularmente, no contexto de pouca oportunidade de ascensão dentro das firmas brasileiras, o novo emprego tem grandes chances de ser tão bom quanto o anterior" (GONZAGA e PINTO, 2014).5 Embora o crescimento econômico nacional da primeira década de 2000 não tenha sido excepcional, foi criado um perfil de demanda por trabalho favorável a rotatividade, pois se concentrou em empregos de menor produtividade e qualificação profissional. A demanda por trabalhadores mais qualificados, nesta mesma década, foi relativamente reduzida, propiciando a criação de um número limitado de postos de trabalho de maior qualidade.

A economia brasileira possui um tipo de crescimento econômico favorável a rotatividade. Almeida e Guilhoto (2006) analisam a correlação entre o crescimento econômico setorial brasileiro e suas respectivas distribuiçôes de renda. Utilizando a matriz insumo produto do IBGE (2002) os autores construíram estimativas para 39 setores econômicos e concluem “(...) que os setores que mais contribuíram para o crescimento econômico diferem daqueles que melhoram a distribuição de renda". Sendo assim, uma inferência possível desse resultado é que o crescimento econômico setorial brasileiro estabelece um tipo de trade-off com a distribuição de renda do trabalho. Outra inferência possível desse mesmo resultado matemático diz respeito ao fato de que o crescimento econômico nacional não distribui renda, porque os seus principais setores, do ponto de vista produtivo, são os piores sob a ótica distributiva. Ou seja: o crescimento econômico brasileiro é estimulado por

5 Embora a maior parte dos pedidos de desligamentos (demissões) venha do próprio empregador, desligando o trabalhador sem justa causa, há uma discussão na literatura nacional que busca identificar se os benefícios, como FGTS, multa e seguro-desemprego, estimulam o trabalhador a optar pelo desligamento. Macedo e Chahad (1985 apud DIEESE, 2011) obtiveram resultados que indicam que o FGTS estimula a rotatividade numa proporção pouco acentuada. Ramos e Carneiro (2002) fazem um contraponto a correlação entre benefícios e rotatividade, com resultados econométricos para a década de 1990, que apontam para uma correlação negativa entre a expansão dos benefícios do desligamento e a taxa de rotatividade. Também ocorre no mercado de trabalho nacional uma prática entre empregadores e empregados para simular que a demissão não é por justa causa, para que o empregado se aproprie do FGTS. "Em muitos casos, o empregador participa deliberadamente desta operação, simulando que deseja demitir, quando na verdade a separação se dá por vontade do empregado" (RAMOS e CARNEIRO, 2002). 
setores mais tradicionais com elevadas dispersóes salariais e com potencial para estimular a rotatividade, porque criam, por meio do crescimento econômico, ocupações de baixa e média qualificação que são indutoras da rotatividade.

As estruturas produtivas, de emprego e salarial da indústria de transformação brasileira mostram-se capazes de estimular tipos distintos de demanda por trabalho, mantendo, ainda, a tradicional polarização no emprego, nos salários e no produto. Poucas atividades parecem ter absorvido inovaçôes tecnológicas, uma vez que são poucas as de elevada produtividade. Há um conjunto de atividades com comportamento intermediário em termos de produtividade e produto, capazes de demandar um tipo de qualificação de trabalho com rendimentos medianos, não desprezíveis perto da média nacional (porque a média nacional é baixa), mas com baixa capacidade de mudar estruturalmente a distribuição da renda do trabalho da indústria de transformação. Salários mais baixos situados entre 1 e 2 mínimos ocupam um número relativamente elevado de trabalhadores. Estes níveis salariais propiciam a manutenção da rotatividade no mercado de trabalho nacional.

A estrutura produtiva dos serviços possui poucas atividades claramente absorvedoras e geradoras de tecnologias capazes de propagar uma dinâmica evolutiva neoschumpeteriana, embora existam avanços moderados em atividades de maior intensidade tecnológica. Contudo, essas poucas atividades de maior produtividade do trabalho que remuneram mais, geram menos postos de trabalho, distanciando-se de um número elevado de ocupados em atividades terciárias de remunerações próximas ao salário mínimo. Com essa estrutura produtiva predominantemente composta por atividades com baixas e médias intensidades tecnológicas, espera-se uma demanda de trabalho com salários e rendimentos também baixos e médios. Sendo assim, a demanda por trabalho mais qualificado nos serviços fica restrita a um grupo relativamente pequeno de atividades terciárias, sugerindo que a queda da desigualdade de renda do trabalho ocorrida na primeira década de 2000 não se associa a um processo intenso e amplo de modernização produtiva dos serviços totais, mas apenas de algumas de suas atividades. ${ }^{6}$ A rotatividade encontra um espaço propício nesta ausência de modernização produtiva.

6 Camillo (2014), ao analisar a estrutura produtiva terciária nacional na primeira década de 2000, concluiu que a estrutura produtiva terciária é polarizada por poucos serviços intensivos em tecnologia e por um expressivo número de atividades terciárias de baixa e média intensidades tecnológicas. 
Apesar das inovações tecnológicas na agropecuária concentrarem-se nas maiores propriedades (apenas $8 \%$ delas), a produtividade total dos fatores na agropecuária nacional cresceu significativamente no período compreendido entre os dois últimos censos agropecuários (de 1996 a 2006), sugerindo que tal produtividade expandiu-se principalmente nas maiores propriedades. Esse crescimento da PTF é compatível com uma "modesta" mudança na composição da estrutura produtiva agropecuária nacional, compreendida entre 1996 e 2006. Diante dessa "modesta” mudança na composição produtiva, o mercado de trabalho agropecuário também continua marcado por ocupações predominantemente de baixas remunerações, distantes das poucas bem remuneradas. Sem a modernização da maioria das atividades agropecuárias, ficam mantidos os empregos de baixa produtividade e qualificação, que possuem altas taxas de rotatividade.

A estrutura produtiva nacional usufrui de um mercado de trabalho flexível. "Uma das principais características do mercado de trabalho formal brasileiro é a ampla flexibilidade contratual” (DIEESE, 2011). Esta flexibilidade permite que se contrate e se demita milhões de trabalhadores anualmente. Esta flexibilidade se manifesta na curta duração do emprego formal, com aproximadamente $64 \%$ dos contratos sendo interrompidos, em 2009, antes de se completar um ano (DIEESE, 2011). O tempo médio de duração do emprego aproxima-se de 4 anos, distanciando-se muito de um conjunto de economias, comprometendo eventuais programas de qualificação dentro das empresas. Com menor qualificação se compromete parte dos ganhos de produtividade do trabalho que poderiam ser obtidos no próprio posto de trabalho, estimulando o rebaixamento salarial por meio desta elevada rotatividade. Setorialmente, destacam-se pela elevada rotatividade a construção civil (108\%), o setor agrícola (98\%), os serviços (54\%) e a indústria de transformação (50\%) (DIEESE, 2011).

Embora se admita a flexibilidade no mercado de trabalho brasileiro, há abordagens que fazem algumas críticas a legislação trabalhista. Pastore (2004) é enfático: "temos leis rígidas e mercado flexível". Para o autor, as leis trabalhistas se aplicam apenas para uma parte dos trabalhadores, porque impõe um alto custo de contratação para os empregadores. ${ }^{7}$ Embora admita a necessidade de um marco

Pastore (2004) estima em 103,5\% os encargos trabalhistas. Contudo, uma ponderação parece relevante: o salário médio sobre o qual estes encargos incidem costumam ser relativamente baixos. 
regulatório para o mercado de trabalho, defende um tipo de regulação menor, além da expansão da livre negociação entre empregados e empregadores (PASTORE, 2004). Outra abordagem que converge para a crítica da legislação trabalhista entende que "o baixo grau de cumprimento da legislação e o fato de que os contratos de trabalho não são bem fiscalizados e monitorados no Brasil também contribuem para a lata rotatividade" (GONZAGA e PINTO, 2014). Desta forma ocorre uma combinação paradoxal de alta rotatividade, rigidez das leis trabalhistas e flexibilidade contratual.

\section{EVIDÊNCIAS EMPÍRICAS: ROTATIVIDADE E SALÁRIOS NO MERCADO DE TRABALHO FORMAL BRASILEIRO}

\subsection{Considerações metodológicas}

O objetivo específico das evidências empíricas é identificar exploratoriamente as conexões entre a rotatividade e os salários no mercado de trabalho formal da economia brasileira. O objetivo secundário é inferir relaçôes entre esta mesma rotatividade e a desigualdade da renda do trabalho no Brasil.

As evidências empíricas estão reunidas em duas partes, totalizando 4 tabelas: uma parte contém estatísticas descritivas (Tabelas 1) e, a outra, algumas regressões lineares simples (Tabelas 2, 3 e 4). As descritivas buscam mostrar a dispersão dos salários dos admitidos e desligados por níveis de escolaridade. Optou-se pelo recorte em níveis de escolaridade com o propósito de se averiguar a seguinte hipótese: a rotatividade comprime mais os maiores salários dos trabalhadores mais qualificados, aproximando-os dos menores e promovendo a queda da desigualdade da renda do trabalho. ${ }^{8}$ Desligados e admitidos representam o movimento que caracteriza a própria rotatividade. $\mathrm{O}$ valor mínimo entre desligados e admitidos dividido pelo estoque de empregos foi a metodologia adotada para se estimar a taxa de rotatividade. Esta metodologia de cálculo é recorrente na literatura nacional (DIEESE, 2011). O hiato salarial entre desligados e admitidos fornece uma primeira medida do quanto a rotatividade pode reduzir os salários dos admitidos. As medidas de

8 Kon e Camillo (2013) enunciaram esta mesma hipótese e a testaram econometricamente, obtendo um resultado aderente com amostras cross section estaduais para o ano de 2009, por meio de análise fatorial. 
dispersão adotadas (desvio-padrão e coeficiente de variação) têm como intenção verificar, parcialmente, as diferenças salariais entre os empregados desligados e admitidos nos vários níveis de escolaridade. Estes níveis de escolaridade também são um tipo de proxy da qualificação do trabalhador.

Com as regressões lineares simples pretende-se dimensionar os impactos da rotatividade sobre os salários $\mathrm{O}$ primeiro grupo de regressōes busca identificar a capacidade da rotatividade em explicar os salários dos admitidos, os salários médios dos empregados formais, a produtividade do trabalho da economia brasileira e a massa salarial dos empregados formais. É usual na literatura econométrica a construção de equações salariais Mincerianas, que possuem como variáveis explicativas proxies do capital humano, como a escolaridade e a experiência. A inclusão da rotatividade como variável explicativa dos salários é uma tentativa exploratória de inclusão de uma variável ligada a demanda por trabalho.

O segundo grupo de regressões simples reúne variáveis representativas dos salários médios dos admitidos por nove níveis de escolaridade. Os admitidos foram escolhidos porque representam os trabalhadores que substituem a maior parte dos desligados pela rotatividade. Como as estatísticas descritivas de apoio já indicavam queda nos salários dos trabalhadores admitidos em relação aos desligados, julgou-se adequado verificar, por meio de regressôes, o quanto a rotatividade comprime os salários destes admitidos. Depois, no terceiro grupo de regressões, buscou-se avaliar os impactos da rotatividade sobre os salários médios, também por níveis de escolaridade, para tentar mensurar o comportamento salarial dos trabalhadores remanescentes, que não foram desligados. É só um exercício exploratório de inferência porque as variáveis proxies representativas dos salários médios reúnem os trabalhadores admitidos incluídos nas outras regressões anteriores. Ou seja, não foi possível filtrar só os trabalhadores remanescentes, ocorrendo, de certa forma, um tipo de "dupla contagem" que contaminou um pouco as proxies representativas dos salários médios do estoque de empregados.

\subsection{Síntese teórica}

A literatura nacional parcialmente descrita e estilizada na primeira parte desse ensaio destaca dois fatores associados à rotatividade: a estrutura produtiva e a flexibilidade do mercado de trabalho. A estrutura produtiva da economia brasilei- 
ra mantém a prática da rotatividade porque é predominantemente composta por atividades econômicas de baixo ou médio valor agregado, que demandam ocupações com menor qualificação. Desta forma, fica mais fácil para que as empresas pratiquem a rotatividade, pois a substituição do trabalhador menos qualificado é facilitada. Esta facilitação também ocorre por meio da flexibilidade do mercado de trabalho, que atinge, inclusive, os empregos formais, uma vez que é possível ampliar a rotatividade mesmo com uma legislação trabalhista rigorosa. A rotatividade no mercado formal de trabalho brasileiro afeta, em maior medida, os salários dos empregados mais qualificados, pois os hiatos salariais entre seus desligados e admitidos são maiores. Não se verificou na literatura nacional a ocorrência de um processo modernizante da estrutura produtiva, no estilo evolucionário neoschumpeteriano, baseado em inovações, permitindo assim a manutenção de empregos de baixa qualidade mais expostos a rotatividade. Aliás, esta rotatividade costuma reduzir a produtividade do trabalho, pois desestimula a qualificação in the job. Em suma, espera-se que a rotatividade promova o rebaixamento salarial, principalmente dos maiores salários, além de um desestimulo a produtividade do trabalho.

\subsection{Formalização dos testes econométricos e metodologias de cálculo das variáveis}

\subsubsection{Primeiro grupo de regressões lineares simples}

a) $L n$ SalárioMédio_Admitidos $(\operatorname{LnWadm})=f(\operatorname{LnR}$ Rotatividade $)[1]$

b) $L n$ SalárioMédio_Total $(\operatorname{LnWmédio})=f(\operatorname{Ln}$ Rotatividade $)[2]$

c) $L n$ Produtividade_Trabalho $(\operatorname{LnVA} / \mathrm{L})=f(\operatorname{LnR}$ Rotatividade $)[3]$

d) LnMAssa_Salarial $(\operatorname{LnMassaAdm})=f(\operatorname{Ln}$ Rotatividade $)$ [4]

Sendo que:

- $\quad L n S a l a ́ r i o M e ́ d i o \_A d m i t i d o s(L n W a d m)$ : foram transformados em logaritmo natural $(L n)$ os salários médios dos admitidos que constam no Relatório Anual de Informações Sociais (RAIS) de 2015. A amostra cross section utilizada possui 53 atividades da Classificação Nacional de Atividades Econômicas (CNAE) 2.0. Os admitidos são trabalhadores que, em sua quase totalidade, substituem os desligados pela rotatividade. Essa 
variável capta o salário médio dos admitidos no mercado de trabalho formal.

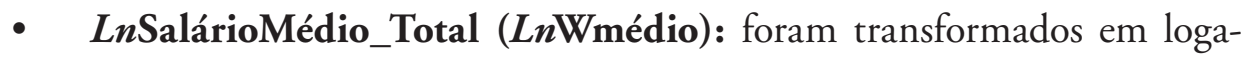
ritmo natural $(L n)$ os salários médios do estoque de empregados, que constam no Relatório Anual de Informações Sociais (RAIS) de 2015. A amostra cross section utilizada possui 53 atividades da Classificação $\mathrm{Na}$ cional de Atividades Econômicas (CNAE) 2.0. Essa variável capta o salário médio do estoque de empregados no mercado de trabalho formal.

- $\quad L n$ Produtividade_Trabalho (LnVA/L): essa variável proxy foi estimada por meio da relação entre o valor adicionado e os ocupados totais, que constam nas Contas Nacionais e depois transformados em logaritmo natural, para o ano de 2014. A amostra cross section utilizada possui 53 atividades da Classificação Nacional de Atividades Econômicas (CNAE) 2.0. A redução de 87 atividades da CNAE 2.0 para 53 ocorreu em função da compatibilização dos dados. A expectativa teórica é que a rotatividade reduza a produtividade do trabalho e desta forma espera-se uma correlação negativa entre a rotatividade e a produtividade do trabalho.

- LnMAssa_Salarial (LnMassaAdm): a massa salarial foi estimada por meio do produto entre o salário médio e o estoque de emprego das 53 atividades selecionadas pela CNAE 2.0 e posteriormente transformada em logaritmo natural. A fonte é a RAIS 2015. Espera-se, teoricamente, que a rotatividade rebaixe esta massa salarial.

- $\quad \operatorname{LnRotatividade~(~} \boldsymbol{n} n$ Rota): esta variável explicativa foi estimada considerando-se o menor número entre admitidos e desligados em relação ao estoque de empregos de cada uma das 53 atividades selecionadas na RAIS 2015. Foi transformada em logaritmo natural. Espera-se que a rotatividade rebaixe os salários selecionados e a produtividade do trabalho. Essa metodologia é usual na literatura nacional.

\subsubsection{Segundo grupo de regressões lineares simples}

a) LnSalárioMédio_Admitidos_Analfabetos $(\operatorname{LnWadmAnalf})=f(\operatorname{LnRotati}$ vidade) [5] 
b) LnSalário Médio_Admitidos_5Incompleto $(\operatorname{LnWadm5incomp})=f(\operatorname{LnRota-}$ tividade) [6]

c) LnSalário Médio_Admitidos_5Completo $(\operatorname{LnWadm} 5$ Completo $)=f(\operatorname{LnRo-}$ tatividade) [7]

d) LnSalárioMédio_Admitidos_Fund_Incompleto $(\operatorname{Ln} W$ admFundInc $)=f(L n$ Rotatividade) [8]

e) LnSalárioMédio_Admitidos_Fund_Completo $(\operatorname{LnWadmFundComp)}=f$ (LnRotatividade) [9]

f) LnSalárioMédio_Admitidos_Médio_Incompleto $($ LnWadmMédInc $)=f$ (LnRotatividade) [10]

g) LnSalárioMédio_Admitidos_Completo ( $\ln$ WadmMédioComp $)=f(\operatorname{LnRo-}$ tatividade) [11]

h) LnSalárioMédio_Admitidos_Superior_Incompleto (LnWadmSupIncomp) $=f(\operatorname{Ln}$ Rotatividade $)[12]$

i) LnSalárioMédio_Admitidos_Superior_Completo $(\operatorname{LnWadmSupcomp})=f$ ( $\operatorname{nnRotatividade)~[13]~}$

Sendo que:

- LnSalárioMédio_Admitidos_Analfabetos (LnWadmAnalf): foram transformados em logaritmo natural $(L n)$ os salários médios dos admitidos analfabetos.

- LnSalário Médio_Admitidos_5Incompleto (LnWadm5incomp): foram transformados em logaritmo natural $(L n)$ os salários médios dos admitidos com até cinco anos de escolaridade incompleta.

- LnSalário Médio_Admitidos_5Completo (LnWadm5Completo): foram transformados em logaritmo natural $(L n)$ os salários médios dos admitidos com cinco anos de escolaridade.

- LnSalárioMédio_Admitidos_Fund_Incompleto (LnWadmFundInc): foram transformados em logaritmo natural $(L n)$ os salários médios dos admitidos com ensino fundamental incompleto.

- LnSalárioMédio_Admitidos_Fund_Completo (LnWamFundComp): foram transformados em logaritmo natural $(L n)$ os salários médios dos admitidos com ensino fundamental completo. 
- LnSalárioMédio_Admitidos_Médio_Incompleto (LnWadmMédInc): foram transformados em logaritmo natural $(L n)$ os salários médios dos admitidos com nível médio incompleto.

- LnSalárioMédio_Admitidos_Completo (LnWadmMédioComp): foram transformados em logaritmo natural $(L n)$ os salários médios dos admitidos com escolaridade média completa.

- LnSalárioMédio_Admitidos_Superior_Incompleto (LnWadmSupIncomp): foram transformados em logaritmo natural $(L n)$ os salários médios dos admitidos com nível superior incompleto.

- LnSalárioMédio_Admitidos_Superior_Completo (LnWadmSupcomp): foram transformados em logaritmo natural $(L n)$ os salários médios dos admitidos com nível superior.

Todas as amostras cross section utilizadas possuem 86 atividades da Classificação Nacional de Atividades Econômicas (CNAE) 2.0 e foram obtidas do Relatório Anual de Informações Sociais (RAIS) de 2015.

3.3.3. Terceiro grupo de regressões lineares simples

a) $L n$ SalárioMédio_Analfabetos $(\operatorname{LnWAnalf})=f(\operatorname{Ln}$ Rotatividade $)[14]$

b) $L n$ Salário Médio_5Incompleto $(L n W 5$ incomp $)=f(\operatorname{Ln}$ Rotatividade) [15]

c) $L n$ Salário Médio_5Completo $(\operatorname{LnW}$ 5Completo $)=f(\operatorname{Ln}$ Rotatividade $)$ [16]

d) $L n$ SalárioMédio_Fund_Incompleto ( $L n$ WFundInc $)=f(L n$ Rotatividade $)$ [17]

e) LnSalárioMédio_Fund_Completo $(\operatorname{LnWFundComp})=f(\operatorname{LnR}$ Rotatividade $)$ [18]

f) LnSalárioMédio_Médio_Incompleto $(\operatorname{LnWMédInc)}=f(\operatorname{LnRotatividade})$ [19]

g) $L n$ SalárioMédio_Completo $(L n W M e ́ d i o C o m p)=f(L n$ Rotatividade $)$ [20]

h) LnSalárioMédio_Superior_Incompleto $(\operatorname{LnWSupIncomp})=f(\operatorname{Ln}$ Rotatividade) [21]

i) LnSalárioMédio_Superior_Completo $(L n W S u p C o m p)=f(L n$ Rotatividade) [22] 
Sendo que:

- $\quad$ LnSalárioMédio_Analfabetos (LnWAnalf): foram transformados em logaritmo natural $(L n)$ os salários médios dos estoques de empregados analfabetos.

- LnSalário Médio_5Incompleto ( $\operatorname{nnW}$ Sincomp): foram transformados em logaritmo natural $(L n)$ os salários médios dos estoques de empregados com até cinco anos de escolaridade incompleta.

- LnSalário Médio_5Completo ( $\ln$ W5Completo): foram transformados em logaritmo natural $(L n)$ os salários médios dos estoques de empregados com cinco anos de escolaridade.

- LnSalárioMédio_Fund_Incompleto ( $L n W F u n d I n c)$ : foram transformados em logaritmo natural $(L n)$ os salários médios dos estoques de empregados com ensino fundamental incompleto.

- LnSalárioMédio_Fund_Completo (LnWFundComp): foram transformados em logaritmo natural $(L n)$ os salários médios dos estoques de empregados com ensino fundamental completo.

- LnSalárioMédio_Médio_Incompleto (LnWMédInc): foram transformados em logaritmo natural $(L n)$ os salários médios dos estoques de empregados com nível médio incompleto.

- LnSalárioMédio_Completo (LnWMédioComp): foram transformados em logaritmo natural $(L n)$ os salários médios dos estoques de empregados com escolaridade média completa.

- LnSalárioMédio_Superior_Incompleto ( $\ln W$ WupIncomp): foram transformados em logaritmo natural $(L n)$ os salários médios dos estoques de empregados com nível superior incompleto.

- LnSalárioMédio_superior_Completo (LnWSupcomp): foram transformados em logaritmo natural $(L n)$ os salários médios dos estoques de empregados com nível superior.

Todas as amostras cross section utilizadas, para todas as variáveis dos três grupos de regressões, possuem entre 83 e 86 atividades da Classificação Nacional de Atividades Econômicas (CNAE) 2.0. A fonte é Relatório Anual de Informações Sociais (RAIS) de 2015. 
-• Economia Brasileira em Debate

\subsection{Resultados}

\section{a) Estatísticas descritivas}

Tabela 1 Salário Médio dos Desligados e Admitidos no Mercado de Trabalho Formal e Hiato Salarial. Brasil. 2015.

\begin{tabular}{|c|c|c|c|c|c|}
\hline Níveis de escolaridade & $\begin{array}{c}\text { Média } \\
\text { RS }\end{array}$ & $\begin{array}{c}\text { Desvio } \\
\text { padrão_R\$ }\end{array}$ & $\begin{array}{c}\text { Coeficiente } \\
\text { variação }(\%)\end{array}$ & $\begin{array}{c}\text { Hiato salarial } \\
\text { desl./adm. }\end{array}$ & $\mathbf{N}$. \\
\hline Brasil_Desligados & 1911 & 1091 & 57 & & 87 \\
\hline Brasil_Admitidos & 1594 & 782 & 49 & & 87 \\
\hline Hiato Salarial_Desl/Adm \% & & & & 20 & \\
\hline Analfabetos_Desligados & 1080 & 225 & 21 & & 83 \\
\hline Analfabetos_Admitidos & 1010 & 126 & 12 & & 83 \\
\hline Hiato Salarial_Desl/Adm & & & & 7 & \\
\hline 5 incompletos_Desligados & 1218 & 279 & 23 & & 86 \\
\hline 5 incompletos_Admitidos & 1086 & 155 & 14 & & 86 \\
\hline Hiato Salarial_Desl/Adm & & & & 12 & \\
\hline 5 completos_Desligados & 1301 & 346 & 27 & & 86 \\
\hline 5 completos_Admitidos & 1142 & 364 & 32 & & 86 \\
\hline Hiato Salarial_Desl/Adm & & & & 14 & \\
\hline Fund. Incompleto_Desligados & 1229 & 294 & 24 & & 86 \\
\hline Fund.Incompleto_Admitidos & 1068 & 144 & 13 & & 86 \\
\hline Hiato Salarial_Desl/Adm & & & & 15 & \\
\hline Fund. Completo_Desligados & 1332 & 321 & 24 & & 86 \\
\hline Fund. Completo_Admitidos & 1166 & 169 & 14 & & 86 \\
\hline Hiato Salarial_Desl/Adm & & & & 14 & \\
\hline Médio Incompleto_Desligados & 1142 & 250 & 22 & & 86 \\
\hline Médio Incompleto_Admitidos & 983 & 149 & 15 & & 86 \\
\hline Hiato Salarial_Desl/Adm & & & & 16 & \\
\hline Médio Completo_Desligados & 1459 & 418 & 29 & & 86 \\
\hline Médio Completo_Admitidos & 1256 & 224 & 18 & & 86 \\
\hline Hiato Salarial_Desl/Adm & & & & 16 & \\
\hline Superior Incompleto_Desligados & 1994 & 639 & 32 & & 86 \\
\hline Superior Incompleto_Admitidos & 1593 & 426 & 27 & & 86 \\
\hline Hiato Salarial_Desl/Adm & & & & 25 & \\
\hline Superior Completo_Desligados & 4420 & 1891 & 43 & & 86 \\
\hline Superior Completo_Admitidos & 3435 & 1290 & 38 & & 86 \\
\hline Hiato Salarial_Desl/Adm & & & & 29 & \\
\hline
\end{tabular}

Fonte: Relatório Anual de Informações Sociais. RAIS. 2015. Elaboração própria. 
Os hiatos salariais entre desligados e admitidos mostram que a rotatividade comprime os salários. Para Brasil, este hiato estimado atingiu 20\%. Além deste hiato salarial nacional, há uma forte desigualdade salarial dentro dos admitidos e dos desligados, sugerindo uma elevada desigualdade de renda. Excetuando-se os empregados com 5 anos completos de escolaridade, verifica-se um padrão: a dispersão salarial das atividades utilizadas, obtida pelo coeficiente de variação, mostra que os admitidos possuem menor dispersão em relação aos desligados, sugerindo que o processo de rotatividade diminui a desigualdade salarial, além de também reduzir o salário médio. ${ }^{9}$ Desligados para a economia brasileira possuem uma elevada dispersão salarial de $57 \%$, enquanto os admitidos possuem uma taxa de $42 \%$ (também elevada, porém menor).

Admitidos e desligados analfabetos apresentaram os menores hiatos e as menores dispersōes salariais, indicando que predomina uma relativa homogeneidade salarial para este nível salarial. A dispersão salarial para os analfabetos admitidos e desligados é relativamente pequena, sugerindo uma desigualdade de renda relativamente menor.

Há uma aparente similaridade entre os seguintes desligados e admitidos por níveis de escolaridade: com 5 anos incompletos; com fundamental incompleto; com fundamental completo; médio incompleto e médio completo. São similares na dispersão salarial e nos hiatos salariais. A magnitude dos seus salários também apresenta uma relativa similaridade. Estas proximidades sugerem que a rotatividade no mercado de trabalho formal brasileiro comprime os salários dos trabalhadores com baixa e média qualificação e os diferencia com um padrão próximo.

Para os trabalhadores formais com nível superior a dispersão salarial e o hiato salarial entre desligados e admitidos se ampliam em relação aos outros níveis de escolaridade, atingindo $29 \%$. Estes resultados mostram que poderá ocorrer uma compressão salarial maior para os níveis mais elevados de qualificação, aproximando-os dos menores salários da hierarquia salarial e assim diminuindo o leque salarial.

9 Kon e Camillo (2013) construíram um modelo de análise fatorial com amostras cross section estaduais para o ano de 2009, para todos os ocupados da PNAD, e obtiveram um resultado que também indica que a rotatividade se correlaciona negativamente com a desigualdade da renda do trabalho (Gini). 
•• Economia Brasileira em Debate

b) Regressões simples

Tabela 2 Regressões simples. Brasil, 2015.

\begin{tabular}{|l|c|c|c|c|}
\hline \multicolumn{5}{|c|}{ Variável explicativa: rotatividade } \\
\hline \multicolumn{1}{|c|}{ Variáveis dependentes } & $\begin{array}{c}\text { Beta } \\
\text { Padronizado }\end{array}$ & $\begin{array}{c}\mathbf{R 2} \\
\text { Ajustado }\end{array}$ & $\begin{array}{c}\mathbf{t} \\
\text { Student }\end{array}$ & N. \\
\hline Salário Médio_Admitidos (LnWAdm) & $-0,56$ & 0,30 & $-4,8$ & 53 \\
\hline Salário Médio_Total $(\operatorname{LnW}$ Wmédio $)$ & $-0,57$ & 0,31 & $-4,9$ & 53 \\
\hline Produtividade do Trabalho $(\operatorname{LnVA} / \mathrm{L})$ & $-0,37$ & 0,12 & $-2,9$ & 53 \\
\hline Massa Salarial_Admitidos $(\operatorname{Ln} \mathrm{MassaAdm})$ & 0,30 & 0,07 & 2,2 & 53 \\
\hline
\end{tabular}

Fontes: Relatório Anual de Informaçôes Sociais. RAIS 2015 e Contas Nacionais 2014. Elaboração própria.

A rotatividade mostrou-se significativa nas quatro regressões, mas o sinal do beta padronizado da última regressão (massa salarial dos admitidos_LnMassaA$\mathrm{dm}$ ) não corresponde a expectativa teórica, porque esperava-se que a rotatividade comprimiria a massa salarial dos admitidos.

Além de correlacionar-se negativamente com os salários dos admitidos ( $L n W A d m)$ e com o salário médio do estoque de empregados ( $L n W m e ́ d i o)$, a rotatividade também pode reduzir a produtividade do trabalho (LnVA/L). Comprimir a produtividade compromete a expansão dos salários, embora esta mesma produtividade do trabalho não seja integralmente transferida para os salários na economia brasileira, em função das imperfeiçôes em seu mercado de trabalho formal.

Os vários níveis de escolaridade, para os admitidos, apresentam resultados que convergem com os hiatos salariais descritos anteriormente na tabela 2. Essa convergência nos resultados pode ser visualizada nos betas padronizados significativos: com o aumento da escolaridade, principalmente a partir do nível médio de escolaridade, nota-se que a rotatividade amplia sua capacidade de redução dos salários dos admitidos. Para os níveis de baixa e média qualificação (analfabetos, 5 anos incompletos e completos e fundamental incompleto) a rotatividade mostrou-se não significativa para influenciar os respectivos salários. Desta forma, a rotatividade poderá reduzir os maiores salários no mercado de trabalho formal, aproximando-os dos menores. As menores compressões salariais para os empregados com menor escolaridade talvez tenham ocorrido em função de uma força contrária à rotatividade, representada pela valorização do salário mínimo. 
Tabela 3 Regressões Simples por Níveis de Escolaridade dos Admitidos. Brasil_2015.

\begin{tabular}{|l|c|c|c|c|}
\hline \multicolumn{4}{|c|}{ Variável explicativa: rotatividade (LnRota) } \\
\hline \multicolumn{1}{|c|}{ Variáveis } & $\begin{array}{c}\text { Beta } \\
\text { Dependentes }\end{array}$ & $\begin{array}{c}\text { R2 } \\
\text { Padronizado }\end{array}$ & $\begin{array}{c}\text { t } \\
\text { Ajustado } \\
\text { Student }\end{array}$ & N. \\
\hline $\begin{array}{l}\text { Salário Médio_Admitidos_Analfabetos } \\
\text { (LnWadmAnalf) }\end{array}$ & 0,50 & 0,24 & 5,3 & 86 \\
\hline $\begin{array}{l}\text { Salário Médio_Admitidos_5 incompleto } \\
\text { (LnWadm5incomp) }\end{array}$ & $-0,14$ & $\mathbf{0 , 0 0 7}$ & $-1,3$ & 86 \\
\hline $\begin{array}{l}\text { Salário Médio_Admitidos_5 Completo } \\
\text { (LnWadm5completo) }\end{array}$ & $-0,03$ & $-\mathbf{0 , 1 0}$ & $-0,26$ & 86 \\
\hline $\begin{array}{l}\text { Salário Médio_Admitidos_Fund_ } \\
\text { Incompleto (LnWadmFundInc) }\end{array}$ & $-0,09$ & $\mathbf{- 0 , 0 0 3}$ & $-0,87$ & 86 \\
\hline $\begin{array}{l}\text { Salário Médio_Admitidos_Fund_Completo } \\
\text { (LnWadmFundComp) }\end{array}$ & $-0,24$ & 0,05 & $-2,23$ & 86 \\
\hline $\begin{array}{l}\text { Salário Médio_Admitidos_Médio_ } \\
\text { Incompleto (LnWadmMédInc) }\end{array}$ & $-0,36$ & 0,12 & $-3,58$ & 86 \\
\hline $\begin{array}{l}\text { Salário Médio_Admitidos_Médio_ } \\
\text { Completo (LnWadmMédComp) }\end{array}$ & $-0,23$ & 0,04 & $-2,14$ & 86 \\
\hline $\begin{array}{l}\text { Salário Médio_Admitidos_Superior_ } \\
\text { Incompleto (LnWadmSupInc) }\end{array}$ & $-0,36$ & $-3,57$ & 86 \\
\hline $\begin{array}{l}\text { Salário Médio_Admitidos_Superior_ } \\
\text { Completo (LnWadmSupComp) }\end{array}$ & & $-0,01$ & 0,15 & 86 \\
\hline
\end{tabular}

Fonte: Relatório Anual de Informações Sociais. RAIS. 2015. Elaboração própria.

A capacidade em reduzir os salários médios do estoque dos empregados por níveis de escolaridade se amplia. Esta ampliação na capacidade explicativa da rotatividade pode estar associada ao fato de que neste salário médio estão somados os salários dos admitidos, anteriormente estimados, com os salários dos trabalhadores remanescentes. Há margem para se levantar uma hipótese adicional: a rotatividade, além de reduzir principalmente os salários maiores, parece inibir eventuais reivindicações salariais dos trabalhadores remanescentes.

\section{CONSIDERAÇÕES FINAIS}

A rotatividade no mercado de trabalho formal brasileiro se mantém porque a estrutura produtiva nacional demanda empregos, predominantemente, de baixa e 
média qualificação. Os trabalhadores destes empregos são substituídos com uma relativa facilidade, porque também as empresas usufruem da flexibilidade do mercado de trabalho nacional, mesmo diante de uma extensa e intrincada legislação trabalhista. $\mathrm{O}$ crescimento econômico apenas expande esta estrutura sem modificá-la qualitativamente. Desta forma, cria-se e se mantém empregos de menor qualificação que são mais suscetíveis a rotatividade. Esta mesma rotatividade compromete, ainda mais, a eficiência da estrutura produtiva, ao comprimir sua produtividade do trabalho. Com uma produtividade baixa, não se espera ganhos salariais expressivos, principalmente para os menores salários que poderiam se ampliar caso se desencadeasse um processo de modernização baseado em inovações tecnológicas.

As evidências empíricas são para o ano de 2015, recessivo para a economia brasileira. A recessão, combinada a uma oferta de trabalho ampla, tende a comprimir os salários naturalmente. Combinando esta compressão salarial esperada, decorrente da interação entre o crescimento econômico negativo, a oferta de trabalho abundante com uma demanda por trabalho reduzida, mais a rotatividade, tem-se um elevado rebaixamento salarial no mercado de trabalho nacional, em especial ao mercado formal. Este rebaixamento de parte expressiva dos salários, gerado pela rotatividade, é visível na relação entre os salários dos desligados e dos admitidos. Os coeficientes negativos das regressões lineares simples para os admitidos foram maiores para os empregos de maior qualificação, indicando que o rebaixamento salarial é maior para este nível da hierarquia salarial. Os hiatos salariais entre desligados e admitidos também foram maiores para os empregos com níveis maiores de escolaridade, como os de nível superior incompleto e completo. Uma inferência possível destes resultados empíricos para a distribuição da renda do trabalho sugere que a desigualdade de renda do trabalho, embora continue elevada, poderá cair em função da aproximação dos maiores salários dos empregos com nível superior com os menores salários dos menos qualificados. Contudo, será uma queda gerada por duas causas: o rebaixamento salarial dos maiores salários gerado pela rotatividade e pela interação entre a demanda de trabalho fraca e concentrada em empregos de baixa qualidade; de outro lado, a coexistência com uma estrutura produtiva que não se moderniza satisfatoriamente. Um processo de modernização produtiva, baseado em inovações tecnológicas, poderá estimular uma demanda por trabalho mais vigorosa e de qualidade, capaz de expandir os empregos mais qualificados e os salários e assim conter o processo intenso de rotatividade do mercado de trabalho brasileiro. 


\section{REFERÊNCIAS}

ALBAN, Marcus. Crescimento sem emprego: o desenvolvimento capitalista e sua crise contemporânea à luz das revoluções tecnológicas. Salvador: Casa da Qualidade, 1999.

ALMEIDA, Leandro de Oliveira e GUILHOTO, Joaquim José Martins. Crescimento econômico e distribuição de renda: uma análise a partir das estruturas econômicas do Brasil contemporâneo. ANPEC, 2006.

BOURGUIGNON, François. The poverty-growth-inequality triangle. 2004. Disponível em: www.ideas.repec.org. Acesso em: 25/04/2011.

CAMILLO, Vladimir Sipriano. Condicionantes da desigualdade da renda do trabalho no Brasil na primeira década de 2000. São Paulo: PUC-SP (pós-doutorado em Economia), 2014.

CASTRO, Rafael Santos e JÚNIOR, Sabino da Silva Pôrto. Efeitos da desigualdade de renda sobre o crescimento econômico no Brasil: uma análise não linear. Perspectiva Econômica, v. 3, n. 1, jan.-jun. 2006.

DEPARTAMENTO INTERSINDICAL DE ESTATÍSTICA E ESTUDOS SOCIOECONOMICOS (DIEESE). Rotatividade e flexibilidade no mercado de trabalho. São Paulo: DIEESE, 2011.

GASQUES, José Garcia; FILHO, José Eustáquio Ribeiro e NAVARRO, Zander. $A$ agricultura brasileira: desempenho, desafios e perspectivas. Brasília: IPEA, 2010.

GONZAGA, Gustavo e PINTO, Rafael Cayres. Rotatividade do trabalho e incentivos da legislação trabalhista. In: Texto para Discussão. Rio de Janeiro: PUC-Rio, 2014.

KON, Anita e CAMILLO, Vladimir Sipriano. Condicionantes da desigualdade da renda do trabalho no Brasil: um modelo econométrico exploratório. In: XIII Encontro Nacional da ABET. Curitiba: 2013.

MINISTÉRIO DO TRABALHO E EMPREGO. Relatório anual de informaçōes sociais (RAIS). Brasília: 2015.

PASTORE, José. Informalidade: estragos e soluçôes. In: Congresso do Coppead. Rio de Janeiro: 2004.

RAMOS, Carlos Alberto e CARNEIRO, Francisco Galrão. Os determinantes da rotatividade do trabalho no Brasil: instituiçôes x ciclos econômicos. In: Nova Economia. Belo horizonte: 12 (2), julho-dezembro. 2002. 
